\title{
Patterns of accountability: an organizational approach to community engagement in museums.
}

\author{
Nuala Morse*
}

\begin{abstract}
This paper considers the divergent and often contradictory registers of 'community engagement' in contemporary UK museum practice. The paper draws on an organizational study of a large local authority museum service and focuses on how community engagement is constructed across a range of museum professionals who use it for different purposes and outcomes. I argue that different departments make sense of community engagement through four patterns of accountability, each with complimentary and divergent logics reflecting a wider range of museum functions, demands and pressures. The tensions that arise are discussed. In the final part, the notion of 'relational accountability' (Moncrieffe 2011) is introduced to re-settle these divergent logics in order to argue for community engagement work that is grounded in a relational practice. The paper contributes to further theoretical and practical engagement with the work of participation in museums by bringing forward an organizational view to highlight the ways in which museum practice is mediated within organizational frames.
\end{abstract}

Keywords: community engagement, accountability, participation, organizational studies, local authority museum.

\section{Introduction}

Community engagement is a central facet of contemporary museum practice. Alongside terms such as participation, collaboration and co-production, community engagement denotes a practice that is responsive and engaged, facilitating dialogue and partnership with communities (Phillips 2003; Adair et al. 2011; Golding and Modest 2013). It is also a contested term which admits various meanings and emphases, which are most directly expressed in the 'spectrum' or 'ladder' metaphor where it is understood along a power continuum from museum control to community control (Arnstein 1969; Simon 2010). The ladder is also the basis for a critique that unravels well-meaning intentions to expose the persistence and pervasiveness of the museum's authority, where the bottom rungs of the ladder represent the most exploitative and tokenistic experiences of engagement for participants (Lynch 2011a).

In this paper, rather than focusing on the experience of participants, I want to explore the perspectives and experiences of those museum professionals 'doing' community engagement work. To this end, I locate my methodology within an organizational approach in order to explore the often-overlooked work-worlds of museums and how these shape particular practices - in my case, community engagement. The aim is to contribute an analysis of community engagement/participation that is situated in everyday organizational workings, thus adding to current discussions of community engagement that have focused on institutional power as the research problem.

To do so, I examine how the concept of community engagement is interpreted and organized by a range of museum professionals across different museum departments - curatorial, outreach and senior management teams - within a UK local council museum service. Drawing primarily on the discursive analysis of interviews, I explore staff's sensemaking processes and analyze the effects of shared as well as divergent ways of making sense of community 
engagement. I suggest that accountability is central to the ways in which museum professionals structure their understanding of community engagement work and identify four repertoires of accountability - local-public, managerial, professional and personal - that are shaped by the demands and pressures of different museum functions, organizational structures and discourses.

The paper is structured as follows: the first part situates the paper in relation to a more detailed discussion of the concept of community engagement in museums. Next, it outlines the values of an organizational approach for researching museum practice, with a particular emphasis on sensemaking as an analytical tool (Weick 1995). The paper then applies this through an empirical study set in a large local authority museum in the UK. I finish the paper by adopting Joy Moncrieffe's (2011) notion of 'relational accountability' in order to re-settle the divergent patterns of accountability put forward in this paper and to propose a more critical community engagement practice that is cognisant of the organizational features and realities of museums.

\section{Community engagement in museums}

A close reading of the literature on community engagement points to two areas of concern for this paper. The first concern has to do with the number of different lineages to the term within academic and museum practice. One expression of community engagement has been driven by demands for minority representation and demands to decolonize collections, particularly ethnography collections (Clifford 1997; Phillips 2003) and wider activist movements to develop socially inclusive and diverse forms of museum practice (notably around issues of gender, diversity, LGBTQ+ and disability) (Sandell 2002; Sandell and Nightingale 2012; Message 2014). Each movement has included calls from outside the sector for more adequate representation in museums and material inclusion in their collections. Community engagement is here framed as the museum's response to these demands, in some cases as part of a response to social inclusion policy (Sandell 2003) or a more pro-active form of socially-engaged practice. On another level, community engagement has been framed as way to develop 'better' knowledge (read here as more accurate or more polyvocal), including better exhibitions, programmes or research (Ames 2003; Tapsell 2014). This is linked to the co-creation of displays and exhibitions (Lynch and Alberti 2010; Lynch 2011a; Morse, et al. 2013). Yet another expression of community engagement presents it as an extension of audience development inspired by the sharing possibilities of Web 2.0, and as a means to ensure the museum's relevance and its success in engaging its contemporary visitors (Simon 2010).

The recent 'participatory turn' in museums is therefore composed of a number of different expressions and origins that are not often acknowledged in discussions of participation or community engagement. While it goes beyond the scope and objective of this paper to consider these lineages in detail ${ }^{1}$, sketching out these different expressions sets out the ways in which concepts such as community engagement admit multiple meanings and emphases within museum contexts. The resulting ambivalence around community engagement is the research problem this piece aims to investigate, doing so by locating this problem within an organizational frame, developed in the second part of this paper.

The second concern has to do with the ways in which the term has become deeply contested and the focus of critical re-assessment, particularly by scholars working within the critical theory tradition. This work has revealed the uneven power dynamics within community engagement programmes (Karp and Lavine 1991; Clifford 1997; Sandell 2002; Peers and Brown 2003; Lynch and Alberti 2010; Boast 2011; Lynch 2011a). At the centre of much of this critique is the contention that the museum ultimately retains control, resulting in engagement work that is paternalistic and tokenistic (Fouseki 2010; Lynch and Alberti 2010; Lynch 2011c). A further focus of this critique is to demonstrate how internal institutional arrangements and practices (of collecting, cataloguing and display) reflect and perpetuate the museums' legacy of racism, sexism and classism (Clifford 1997; Lynch and Alberti 2010; Boast 2011). For many commentators, the failure of participatory practice more generally is its failure to analyze and dismantle institutional power. For Bernadette Lynch, a key museums scholar and practitioner in the UK, the challenge resides in addressing the invisible power at play in museums and resisting institutional 'habits of mind' Lynch $2011 \mathrm{c}: 5$ ). She argues that museums 
exercise a subtle and pervasive form of consensual power that convinces or co-opts museum professionals and participants into what is expected, 'common sense' or inevitable, thereby aligning communities within the values and agenda of the institution (Lynch 2011c, 2011b). This includes the language of 'community engagement' used by professionals, which shapes both the forms of dialogue that are possible and positions participants as passive beneficiaries (Lynch 2011c). Against the invisible power of the institution the good intentions of museum professionals appear to have little force: 'a subtle and coercive power at work in the museum obscures the view (...) so that those involved feel powerless to really analyse or challenge it' (Lynch 2011b: 444; see also Boast 2011).

Discussions of engagement/participation within a dominant critical tradition have therefore focused on making power visible. However, by focusing on institutional forms of power as the research problem, this work has tended to form relatively flat views of the museum from which power flows in a fairly predictable top-down or centre-out ways. There is a clear purpose to this spatial rendering of power as it enables us to follow its commonplace workings; however, it leaves little room for a pragmatic engagement with practice as it takes place on the ground and the ways in which practitioners negotiate, revise or maintain the organizations in which they work. Indeed, to date there has been limited research on the practice of 'doing' community engagement work from the perspectives of museum professionals since the focus has been the experience of participants. ${ }^{2}$ In this paper, I want to argue for an engagement with the museum as an organization that is 'peopled and practiced' (Askew 2009), by placing an emphasis on the experiences and perspectives of museum professionals, in order to suggest more provisional arrangements of power that are shaped across everyday organizational features and relationships, and beyond abstract institutional logics. Taking an organizational view, I suggest, shifts our focus on community engagement and its possibilities.

\section{The value of an organizational framework for researching the museum.}

Museum management as a topic of study seems to have come of age in the 1990s to become a mainstream concern. This work has shown the complex arrangements of commerce and politics in which museums now operate and that go alongside the work of preservation, display and access, often within a landscape of marginal public funding (Sandell and Janes 2007). It is undoubtedly clear that museums have developed into more complex organizations with the increasing professionalization of the sector and as more formalized governance regimes have been introduced in the context of an increasingly policy-driven cultural sector. For example in the UK, this has taken place within the roll out of New Public Management via ministerial departments which established a formal mode of governing museums based on efficiency, performance management and accountability (a key term I return to shortly), driven by instrumentalism and a market-orientation (Lawley 2003; Gray 2008; Tlili et al. 2007; O'Neill 2008). While the shift to cultures of audit within a policy context has been well documented, as suggested by the references above, there are fewer recent attempts to analyze the organizational day-to-day of museums as they are experienced by staff. Indeed, the organizational framework implied in museum management studies has not yet been fully oriented towards the everyday experience of those working in museums.

Sharon MacDonald's (2002) Behind the Scenes at the Science Museum is an important theoretical and methodological move in this direction, using ethnography and organizational analysis to understand the complex processes of exhibition making. Another area of work which turns its attention to the organizational features of museums is cultural policy studies which considers how staff implement (or otherwise) policy directives within their situated organizational contexts (Tlili 2008, 2012; Gray 2014; McCall and Gray 2014). Such work highlights the particular dynamics though which practice is framed, performed and constrained. In particular, Tlili has examined how the policy concept of social inclusion was interpreted within UK museums 'by museum professionals who answer to different sets of priorities and use the same language in a different genre, so to speak, a genre of operational professional practice' (Tlili 2008: 124). Here I consider the language of operational professional practice through which staff make sense of community engagement in their organizational contexts. In others words, I am concerned with how professionals speak of community engagement within the day-to-day language of operational procedures in a local council museum. 
The proposal set forth in this paper is to examine the value of an organizational view for researching the museum by drawing on organizational studies. As a broad field of research, organizational studies provides a diverse theoretical base drawing on a range of disciplines to think about organizing processes and patterns (Hatch and Cunliffe 2006). Museums, however, rarely feature as an object of research by organizational theorists, so little direction is provided, though the possibilities are clear. Within this paper, my focus is on the empirical study of professionals' interpretations and concepts from a constructivist perspective, to explore how staff construct and reconstruct their understandings of their organization. To follow this and to establish the significance of organizational members' view, I draw on Weick's (1995) notion of sensemaking, and deploy it as an analytical tool. Weick developed sensemaking as an alternative way of understanding the process of organizing: instead of looking at organizational outcomes (a focus of much early work in organizational studies), sensemaking provides insights into how individuals understand their experiences both as they occur and in retrospect, and how they make sense of their environment. Sensemaking is a useful tool where the task is to explicate how professionals come to understand and take action in their day-to-day work situations, both individually and collectively. Analytically, it is about an interpretive approach, as it is through sensemaking that 'situations, organizations and environments are talked into existence' (Weick et al. 2005: 409).

Taking a sensemaking perspective can help to understand how different meanings are assigned to the same event, action or policy - or in this case, an area of museum work. As a method, it highlights internal incoherence as an 'in-built' and common feature of organizations (Kirkpatrick and Ackroyd 2003). This incoherence is important in explaining the different understanding of areas of museum practice and the 'discursive displacements' (after Tlili 2008) that occur in staff's interpretations and descriptions of this practice. As such, incoherence in organizations should not be dismissed as an anomaly. Recognizing this breaks away from fixed accounts of museums as rational organizations to favour a view of museums where multiple interests, discourses and logics content for authority and influence. This links to the organizational view of the museum as peopled and practiced, with diverse outcomes and effects. To be clear, these interests are themselves also shaped within wider institutional environments (see McCall and Gray 2014), so that the study of sensemaking does not imply an insulated view of the museum. I suggest this requires a grounded critical approach to the museum as organization and an interpretive perspective that is focused on how museum professionals make sense of their work. The organizational lens, I argue, adds a new dimension to work exploring the problematic of community engagement and participation in museums, and sets out a number of implications for theory and practice which are explored in the final part of the paper.

\section{Methodology}

My arguments are grounded in the analysis of semi-structured, in-depth interviews and notes from meetings and conversations collected as part of a detailed ethnographic study of a single case study museum. The article draws on one element of a wider ethnographic research project which aimed to explore the practices of participation in museums, the cultures and structures that enable or impede community engagement work, and staff's perceptions and experiences of 'doing' engagement work.

The case study in this paper is Tyne \& Wear Archives \& Museum (henceforth referred to as 'the Museum'), a multi-sited museum service for four local authorities. It is governed by a joint committee that includes representatives from the four local councils. At the time of the research (2011-2013), it received support and contributions from the four local councils, the Department for Culture, Media and Sport and the Arts Council for England, and employed around 280 staff. Over the research period, the average number of visitors to the different sites was 1.4 million per year. The service holds collections of local and international significance in archives, art, science and technology, archaeology, military and social history, fashion and natural sciences. The rationale behind selecting this museum service for a single in-depth case study was the opportunities it presented in reflecting a microcosm of museum functions and collections types, with the wider aim of suggesting some organizational traits that are applicable to other museums, particularly local authority museums in the UK, which represent a significant section (40\%) of the sector (Lawley 2003). 
A total of 45 members of staff were formally interviewed between late 2011 and early $2013^{3}$ from the different museum departments including outreach ${ }^{4}$, senior management, curatorial, learning, collections, communications, volunteer management, and the development team. The interviews focused primarily on asking staff what they understood by 'community engagement', how it related to their practice, and their perceptions of the barriers to this work. In this paper my focus is on the discursive analysis of 'the operational language' of community engagement (henceforth CE): how staff interpret, define and make sense of CE in different departmental contexts and in relation to their specific roles and responsibilities. The analysis then considers the different ways in which the notion of 'accountability' was repeatedly brought together with the idea of community engagement within the interviews, but framed in a number of different ways as one of the significant themes to come out of the thematic analysis of the wider ethnographic project.

\section{Patterns of accountability in the museum}

As I will demonstrate, there are four patterns of accountability that formed around the interpretations of CE work. Each position of accountability has different operational logics that flow in different directions. The four dimensions represent the different institutional roles of the museum - their public, cultural, social, and increasingly, economic function. These functions reflect the kind of 'museum frictions' mapped out by Kratz and Karp (2006) - the multiple mandates, complex sets of influences and contradictory goals that define museums.

As Gray (2011) argued, there are multiple forms of accountability within museums. Some are common to the public sector: the financial accountability and audit owed to government funding bodies; direct political accountability to local councillor; legal accountability and compliance. There is also a more general public accountability directed at those people for whom the museum exists: 'the public', communities and visitors. Alongside these are other forms of 'temporal' or custodial forms of accountability that are particular to the museum sector: the responsibility of museums to the past (preserving collections), the present (displaying collections for contemporary audiences), and the future (holding objects in trust for future generations) (Gray 2011: 54). Finally, there is the accountability to professional values, set within the context of museum ethics (Marstine 2011). The dynamics of accountability in the museum have been investigated by a small number of studies (Carnegie and Wolnizer 1996; Hetherington 2003; Gray 2011) however, community engagement has not yet been explicitly discussed in terms of this concept.

In the interviews conducted across the museum, accountability and 'being accountable to' were often repeated phrases that staff returned to in the process of making sense of CE and its purpose as they described it to the researcher. Within the public administration context, Sinclair (1995: 219) suggests that accountability 'will be enhanced by recognizing the multiple ways in which accountability is experienced'. She further suggests that accountability can be understood as both something that is felt and as a more abstract authority-scrutiny structure. In the following section I outline the four patterns of accountability that emerged through the accounts gathered. Through this discussion, my aim is to provide a fine-grained analysis of the multiple accountabilities felt by museum professionals, allowing for incoherence to emerge as part of the organizational configurations of museums, before developing a discussion around re-settling accountability in the museum in a practical and community-focused sense.

\section{Local-Public Accountability}

At the broadest level, staff conceptualized CE as part of the public function of museums. One member of the curatorial team described this common sentiment: 'we do community engagement to make our collections and displays relevant to the public which we serve'. ${ }^{5}$ In this conception, CE is linked into an expansive view of the public role of the museum in terms of the primary function of preservation and display. This public role crosses over with the stewardship function: 'all of our collections, they don't belong to us they belong to the people of Tyne \& Wear so we should be promoting access in whatever way is possible'. ${ }^{6}$ At this level, $\mathrm{CE}$ is cast less in terms of its specific activities and more in terms of the principle or ethos of 
the public museum, with a strong emphasis on access. One problematic expression of this public function found its stronger expression in a number of interviews with managers who went on to reframe CE along the lines of audience development: 'community engagement is about audiences - getting audiences in and back again'. ${ }^{7}$ This was an area of tension expressed by staff who felt that some of their colleagues who were most distant from delivering this work did not understand the reciprocal demands of CE (see Lynch 2011b). The slippage between these two terms has been commented upon elsewhere (Tlili 2008) and it indicates the ambivalence around CE, highlighted in the opening section's review of the lineages of term.

In the Museum, the public was specifically imagined as a very local public, as illustrated in the opening quote that signals a museum 'for the people', another common ideal expressed in interviews. The expectation and rhetoric of the museum as 'popular' therefore influenced the ways in which organizational members made sense of CE activities for themselves, whether they actively participated in delivering this work or not. It follows that the first dimension of accountability attached to CE was towards local people, with the museum working on behalf of the local public through a form of local-public accountability. As we begin to consider these responses in terms of accountability, the matter of concern is the direction of its settlement: in the Museum the firmly local version of the public as local people was specifically settled with the discourse of representative democracy, linked to its long-standing governance model as a local authority service. Indeed, in the Museum, governance is assured by a Joint Committee made up of elected representatives from the member councils:

Our strong senior management team provides a clear strategic lead for the organization and the Director reports to a Joint Committee. The support of elected councillors gives both a democratic accountability and a community based focus ${ }^{8}$

Here, accountability is situated at the centre of modern representative democracy as it produces the arrangement through which citizens are connected to their representatives (Bellamy and Palumbo 2010). Within this model decisions and actions are made in the public's interest and for the public 'good'. The museum's governance structures derive legitimacy from having elected sitting on committees who have a mandate from the people by virtue of having been democratically elected. The link in the above document between democratic accountability and community based focus is significant in encapsulating the discussion of CE across management team and how they related CE to their role. In these cases the public role was often discussed in relation to making the case for the public value of the Museum to its committee members and the council as key funder: 'the whole advocacy side of community engagement is important because it helps you to justify your existence'. ${ }^{9}$ Similarly to the way in which CE was displaced above to represent the more unidirectional relation of audience development, one potential consequence of the re-articulation as advocacy is that the distinction between $\mathrm{CE}$ and public relations becomes blurred and its potential impact muted. Through this first form of accountability, then, we can begin to see how the multiple relations of accountability draw out different meanings and uses of CE, and the ways in which they are settled in particular directions and at particular scales.

\section{Managerial Accountability}

Managerialism is best understood as 'an assemblage of regulatory and organizational ideas, values, discourse and practices' (Tlili 2014: 9) established around notions of efficiency and effectiveness and manifest by what anthropologists have termed 'audit culture' Strathern 2000). The focus on efficiency aims to ensure that the taxpaying public is receiving value for money services, while the focus on effectiveness is linked to external and internal regimes of performance management that prescribe specific outcomes against targets and based on (usually numerical) standardized indicators. Monitoring and evaluation are central to efficiency and effectiveness in making museums accountable based on users' needs and wants (but via their definition by Government). This was significant in the Museum as staff spent considerable amount of time reporting on their professional activity in this way.

The language of managerialism was present in the interviews across departments. While all respondents indicated that targets such as visitor numbers were not the most significant 
indicator of the value of museum work, there was recognition that overall performance management was as a fundamental dimension of 'good' museum work, and necessary as it was seen as a way to ensure quality, transparency and accountability:

Ultimately, community engagement, part of it has to be to demonstrate to the people who have given you the money in the first place that you have spent the money in the way that you said you were going to and that you added value to them in however they wanted to engage with you. ${ }^{10}$

Within the managerial frame, the claim is that value for money should deliver a utility return to the public. In The Museum this return was often conceptualized as benefits aligned with local council priorities such as 'stronger and safer communities' or 'strengthening public life'. CE here becomes an instrumental activity through which museum work is aligned to council priorities and where outcomes (often numerical) come to define CE. Naturally, this view was mostly expressed by managers who are responsible for relations with client bodies, but it also found echoes in other staff interviews. In these conceptualizations, CE is operationalized as data, as a collection of numbers; its participants are mostly absent or only appear as percentages or aspirational quotes in final reports to funders. Managerial accountability is settled in theory through evidence of impact and value for money - as such, it is an external pattern of accountability first rendered through data and directed at funders (in particular central government) and the taxpaying public.

The spread of new managerialism has received a lot of academic criticism, in particular, a sustained critique of a form of 'coercive accountability' based on neoliberal techniques of governance that are reshaping public work places and professional identities (Shore and Wright 2000; Tlili 2014). Within the Museum, accountability to the taxpaying public appeared to be internalized in a large proportion of staff identities, whatever their job role and remit:

For me [CE] is fundamentally around the fact that the public pay for these services out of their taxes full stop ${ }^{11}$.

The public pay my salary therefore I am accountable ${ }^{12}$.

However, while there was a widespread consciousness of audit culture, the internalization of the values of audit by staff was not straightforward; it was also resisted in a variety of ways that hold onto the more intrinsic values of museums to signal a wider local-public role and the relevance of the museum. As one member of the Learning Team put it: 'You are constantly going to groups and saying this is your museum, you are paying for it, this is yours. Use it as you would'13; or this curator: 'I think that it offers value for money in a local authority museum that you are engaging people to make sure you are offering a service that they want and a story that they want to hear' ${ }^{\prime 14}$. And finally:

I think there is a commitment to making a difference in the local community and wanting people to feel ownership and to make a more resilient organization because we are responding to people's needs because at the end the day if there isn't a demand for your product then why would you continue to deliver it? So again that ties into value for money but I do think there is a social ethos behind the organization ${ }^{15}$

In this way, the boundaries of the patterns of accountability I describe are also porous, though they have distinct internal logics.

\section{Professional Accountability}

Within the Museum, and across its different sites, many staff espoused a Social History approach (Fleming et al. 1993), or 'history from below', linked to the institutional ethos of a museum 'for the people' and making collection accessible and relevant to the public: 'community engagement probably works easiest with social history I guess and social history displays are probably the best way to display people's histories and people's stories'. ${ }^{16}$ In the Museum, many curatorial and collections management-focused staff described social history as part of their professional practice and professional identities. CE was made sense of along these lines: 
I exist as a curator to collect objects but I think the way I do that sometimes is through community engagement ... so it's a method, it's something that legitimizes what I collect. ${ }^{17}$

Community engagement in that sense is about working with people to tell everyday stories about everyday Newcastle and that's the main premise of social history and that's its strength - so I would see community engagement being mainly in the sense of content in a museum so that history is what people's everyday lives were. But I guess the other way we think about community engagement (...) is co-curation as well - so sharing curatorial decisions in terms of exhibitions. ${ }^{18}$

Examples that were given included a range of CE activities that could be considered along the ladder of participation, from donations and oral histories, to first person interpretation and more proactive collaborative exhibitions processes. Involving local people in telling their own stories was seen by curatorial/collection staff as fundamental to the museum's relevance. In this way, CE was attached to a sense of professional accountability to the principles of social history curatorship. It was described as a tool through which to uphold and meet such professional standards - although it should be made clear that these are not strictly set standards, as museum practice is best understood as a profession in the making (Tlili 2016).

Professional accountability refers to the sense of duty of professionals to adhere to the standards of the professional or expert group of which they are a member ${ }^{19}$ (Harmon and Mayer 1986). In this sense, accountability here can be interpreted in relation to professional standards around the 'better' knowledge of collections through consultation and including multiple interpretations, which was discussed in the earliest part of this paper's discussion of the origins of CE. It is about earning legitimacy for the museum's activities of collection, preservation, interpretation and display, which, however re-worked in relation to communities, is ultimately in the support of professional expertise.

\section{Personal Accountability}

As Sinclair (1995) reminds us, accountability is also something that is felt and can be understood as having a personal form: personal accountability is linked to ethical and moral values, personal conscience and accepting responsibility for affecting the lives of others (Harmon and Mayer 1986). In relation to CE, the expression of personal accountability was more powerfully expressed in those staff 'doing' community engagement work directly - the outreach team in the case of the Museum. It was therefore a very direct form of social responsibility, felt and experienced at close proximity: 'we do [CE] because we believe in it. We want to make a difference to people's lives, and believe we can do this through art and culture'. ${ }^{20}$ Here the focus was working with under-served groups and communities that have largely been excluded from the museum. In the Museum, outreach staff spoke clearly about CE as more than a set of activities or institutional ethos or about collection knowledge, but as a powerful allegiance to communities. For the team, the key priority of CE was to empower people through participation. Fundamentally, CE was understood as a duty of care towards communities (Morse and Munro 2018). As one Outreach staff member put it: 'there is a sense of responsibility to the people you work with on the ground - if you lose that you lose the point of what's being done'. ${ }^{21}$

In this dimension, the relations of accountability focus on the site of the engagement and the relations developed between outreach workers and participants. As such it operates on a much more direct and relational scale and within a moral repertoire. This form of personal accountability can also be understood as an emergent sense of professional accountability within a sensemaking process of articulating community engagement as a form of work. In the next sections I reflect on the effects of the four patterns of accountability described above and the problems that ensue for $\mathrm{CE}$, before proposing the notion of relational accountability as a potential solution.

\section{Discussion: multiple accountabilities in the museum}

In a variety of ways, the data shows how CE is discursively displaced within the operational 
language of organizational members' sensemaking practices and based on their roles within the museum. Museum professionals describe $\mathrm{CE}$ through different forms of accountability towards diverse constituencies: the public, the council, funders, ministerial departments, professional standards, to communities and to themselves. They feel accountable to different things: for ensuring access, for delivering value-for-money, for presenting 'accurate' historical knowledge, and for enabling people to participate in culture. This research shows how CE is understood within and through four patterns of accountability which re-contextualize the meaning of CE within different logics, for example instrumental (i.e. value for money), representative (i.e. governance structures), representational (i.e. value of social history) and moral (i.e. wider social responsibility). In each of these four forms, CE is positioned as either advocacy, as data, as a tool to gain better museum knowledge and as moral responsibility. Each repertoire has different drivers: local or central government policy objectives, funder requirements, professional standards or participant needs, felt as a professional duty of care. The research data shows, like Sinclair's (1995) study, that accountability is multiple, fragmented, and most significantly for the museum, it is constructed along different lines by different museum staff working across different functions and priorities. I want to explore the effects of theses multiple forms of accountability described above and the problems that ensue for CE in the museum.

I suggest that the discursive displacement of CE into different patterns of accountability is a matter of concern because it defines the relationships between the museum and communities along different lines with particular consequences. Indeed, different patterns of accountability flow in different directions: either indirect or direct accountability, either upward or downward accountability. The different positions orient benefits towards different aims: participation is directed at everybody (the 'public'); or aimed at specific groups; or aimed at improving the museum (see also Graham 2011). Clearly, relations of accountability are configured through various politics and priorities that follow power relations and hierarchies, so that museums are more accountable to some relationships than others - or more prosaically, some forms of accountability are privileged over others depending on who makes decisions in museums. In general within the wider ethnographic project in the Museum, upwards and indirect forms of accountability tended to be favoured over downwards and direct relations with participants/ communities, since those who make decisions in museums are nearly always those who are situated in upwards forms of accountability. Because the different patterns of accountability are not explicitly recognized or acknowledged in the museum - either in practice or in the academic literature - decisions in museums are made without reference to these favourings and their effects (what accountability counts and for/to whom). I suggest this therefore signals an important area for further research around the stakes of participation. From a theoretical perspective, this leads us to reconsider the ways in which museums achieve a balance between their different roles, functions and their responsibilities towards different constituents. From a practice perspective, mapping out different patterns of accountability holds the potential to reconsider some of the daily dilemmas of contemporary museum work and how decisions and compromise are reached, and for whom. For example, around decisions concerning income generation from spaces that are usually used by community groups free of charge; or when considering the democratic potential/limits of representative forms of relationships with communities via elected officials; or when considering the issue of 'public interest' in the context of co-produced exhibitions. ${ }^{22}$

In general, it is clear that museum staff can see that there are different models of working with communities (see McSweeney and Kavanagh 2016 for a practitioner perspective). What is more significant and is highlighted through the data, is that museum professionals purposively claim different meanings in relation to their working practices as managers, curators or outreach workers. At same time however, the research shows that these forms of accountability in the museum are not static and not straightforwardly internalized by set groups of professionals. Indeed as can be observed through the interviews, staff could shift from one mode to another, one language to another, sometimes within the course of a sentence:

For museums to make our collections and display relevant to the public which we serve which is more pertinent for local museums because obviously we are funded by local authority and to give voice to communities which have previously 
been under-represented so in the past that has been women and working class people and more recently it has been minority ethnic groups and disabled groups, gay lesbian groups - we have worked with all different sections of society so that people feel empowered they may feel that the museum is relevant to them and their lives and that it is somewhere they can come and enjoy and justifying our position in these strained times. ${ }^{23}$ [Author's emphasis]

This points to the ways in which organizational members continuously negotiate multiple forms of accountability in the museum. As Neyland and Wooglar (2002: 272) make clear in their work on accountability in the university setting, 'the messiness of accountability in action' comes through 'whole series of flows, circuits, connections, disconnections, selections, favourings, accounts, holding to account and attempts at analysis'. As noted above these disconnections, selections and favourings are rarely openly discussed. In her study Sinclair (1995) concludes that the solution is not for administrators to impose a singular form of accountability, but rather 'efforts to enhance accountability should recognize and build upon the processes which enable the construction of a more robust and privately anchored experience of accountability' (1995: 234). In the final part of this paper I consider the notion of 'relational accountability' as an additional and alternative view of accountability in museums that can connect to more privately anchored experiences of the purpose of CE and its democratizing potential.

\section{Towards a relational form of accountability in museums}

The analysis presented in this paper shows that there are different understandings of $\mathrm{CE}$ across the museum and I suggest we can gain a deeper understanding of these differences by framing these through the lexicon of accountability. The problem that ensues for CE is that because these different forms of accountability and their directions are not clearly acknowledged in museums, the balance and compromise through which decisions are made is obscured. However, as the data makes clear, the language of accountability holds a significant currency in the contemporary museum. It is a term that staff regularly used in their interviews: 'I am accountable' was an important marker of museums professionals' identity in a local authority museum and way in which they made sense of the public role of their organization. As such, I suggest accountability holds potential as a solution for more productive forms of CE as an already accepted language within the museum.

While the different patterns of accountability described above all have substantial merit, as primarily representative and technical forms of accountability, they provide an incomplete picture of the accountabilities at stake in the museum. In particular, 'on the ground' relationships with communities are not clearly represented in the museum's current systems of accountability. Instead, these relations are usually confined to the timeframe of a project (see Lynch 2011c) rather than being considered within the wider organizational workings of the museum. Consequently, they are at risk of being easily dismissed by management as that which happens during engagement projects, and therefore not a wider institutional concern.

I suggest that this also happens precisely because the relations with communities are rarely thought of as relations of accountability, in either practice or theory - rather, they are about reciprocity, trust, dialogue, partnership or collaboration (Clifford 1997; Lynch and Alberti 2010; Golding and Modest 2013; Lynch 2013). While these terms all account for the relational dimensions of CE work, they are part of a language that operates outside of the organizational frame of the museum and the ways in which museum professionals negotiate their roles and their work day-to-day. As such, I suggest that they have less purchase in the organizational procedures of the museum.

Returning then to accountability in the museum, I draw on the idea of relational accountability from Joy Moncrieffe (2011) in order to bring the relational dimension of CE into the fray of museum accountabilities, alongside the representative, managerial and professional forms. Moncrieffe writes about relational accountability in the context of development and civil rights work. For Moncrieffe (2011: 39), relational approaches move away from the conventional approaches to accountability that are 'macro-institutional' and broadly asocial. Relational approaches are framed in a critical human-and society-centred approach: starting from the view that humans are primarily 'social creatures and actors', relational approaches 'recognize that 
wellbeing, freedoms, capacities, willingness to act as well as the quality of political involvement also depend on social relationships' (2011: 40).

As such it is a contingent and specific accountability that focuses on the conditions for participation. Applied to the museum, it is about relations that are cultivated between the museum institution, museum workers, communities and participants, where the quality of such relations depends on people's capacity to engage in dialogue and meaningfully represent and defend their interests. Relational accountability goes beyond monitoring and evaluation and checks and balances to address the quality of the museum's relationships with its different constituents, and the mechanisms through which constituents can talk back to the museum and hold it accountable. Relational accountability therefore challenges those parts of the museum that approach communities at a distance. The point here is not to say that all managers (as decision-makers) need to be always 'on the ground', but rather that they become much more aware and sensitive to local engagement work. Relational approaches aim for more horizontal relationships in museums, rather than only upwards and indirect ones.

Arelational approach to accountability in the museum does not mean a rejection of public accountability or other forms of museum accountability, or a demand for a strictly relational ethics, where the museum is only accountable to those who participate. Moncrieffe's relational approach to accountability recognizes the value of technical approaches as institutional mechanisms for regulating power in the public's interest, but goes further to question whether and how these mechanisms are just, and whether they foster just decision-making procedures. In practice then, a starting premise for relational accountability in the museum will require that staff reflect more openly and more often their intentions and values, in order that they can map out patterns of accountability in their museums. As Sinclair (1995: 233) makes clear: 'the management of one's own and other's accountabilities requires strategies tied to understanding of language and ideology, values and ethics, emotion and motivation'. Engaging in discussion of emotion and motivation can enable museum workers to explore some of the tensions that reside in their work and to make room for more personally anchored motives for being accountable.

In relation to CE work, relational accountability means, for example, that front line workers are more open to participants about the parameters of the project, and finding more open and collaborative ways negotiate professional standards, organizational procedures and notions of 'public interest'. Or it might mean establishing other mechanisms such as the presence of community members on management boards. It also requires that front line staff are recognized by managers as intermediaries so that community interests can be better heard and defended in the processes of institutional balance and decision-making that take place inside the museum. Enabling communities to defend their interest with a greater understanding of how museums operate - organizationally and institutionally - can secure more productive engagement/participation work.

The deployment of relational accountability can therefore be seen as providing a framework and a politics of museum practice that operates from within the organizational logics of the museum. It is an analytical shift also which itself opens up the possibilities for change as working through 'adjustments' (Bennett 1992: 32; Graham 2012: 568), and holds significant political possibilities for reframing participatory practice.

\section{Conclusion}

Moving towards more participatory and engaging modes of working continues to be a central concern of the museum and understanding the power dynamics that mark this work is a key area of scholarly interest. Much of this work has focused on the perspective of participants and there is a propensity to understand museums as bounded by totalizing institutional practices and top-down orderings of power. By contrast, this paper has sought to approach the museum as a peopled organization and to examine the perspectives of museum professionals 'doing' community engagement directly and at a distance. The research reveals different conceptions of community engagement and proposes that these can be productively examined through attention to their discursive attachment to different forms of accountability. By drawing attention to the language and genres of operational professional practice, the findings reveal how community engagement is framed by organizational, institutional, professional and personal concerns. 
There are methodological as well as substantive and practical implications to this research. Methodologically, the paper highlights the value of organizational studies in providing other conceptual frames to examine the often-overlooked organizational workings of museums and how museums professionals make sense of these dynamics. This point towards methods that are attentive to organizational member's experiences and sensemaking practices, as well as pointing towards interpretive and grounded methodologies. Approaching the museum as organization also points to other analytical concepts for understanding practice and how these might be utilized to establish other way of thinking through forms of engagement and participatory practice in the museum. In this paper I have argued that framing this work through notions of accountability, including relational accountability, holds significant political possibilities for reframing participatory practice. For museum professionals, the research suggests the need to recognise and analyse the different patterns of accountability in the museum and their consequences, and to make space for privately anchored and relational forms of accountability alongside structural and technical forms.

Received: 3 July 2018 Finally Accepted: 23 July 2018

\section{Acknowledgements:}

I would like to thank all the museum staff who participated in the research. My thanks to the two anonymous reviewers and to Andrea Witcomb, Bethany Rex and Sarah Richardson, as well as colleagues in the School of Museum Studies, University of Leicester, for their careful editorial comments that have enabled me to strengthen this paper. This work was supported by the Economic and Social Research Council [grant number ES/I902074/1].

\section{Notes}

1 For a further discussion, see Helen Graham 2010 'Participation, Intellectual Property and Informed Consent: A literature review', http://partnershipandparticipation.wordpress.com/, accessed 8th January 2017.

2 A significant exception here is the noteworthy contribution from Munro (2014) on the emotional labour of community engagement workers.

3 It is important to note that the study took place against a backdrop of continued austerity and deepening cuts to the UK museum sector; while this context was significant to the wider study, it is less so to the analysis presented here, as the understanding of CE was set within a much longer time-frame within which the Museum had been undertaking this work.

4 Research with this group formed the main focus of the ethnographic work.

5 Curatorial Team member, interview by author, digital recording, 2012.

6 Curatorial Team member, interview by author, digital recording, 2012.

7 Management Team member, interview by author, digital recording, 2012.

8 Extract from TWAM funding bid, 2010.

9 Management Team member, interview by author, digital recording, 2012.

10 Management Team member, interview by author, digital recording, 2012.

11 Collections Team member, interview by author, digital recording, 2011.

12 Learning Team member, interview by author, digital recording, 2011.

13 Learning Team member, interview by author, digital recording, 2012. 
Curatorial Team member, interview by author, digital recording, 2011.

Curatorial Team member, interview by author, digital recording, 2013.

Indeed several curators were part of the Social History Curators Group, a UK professional group 'formed to improve the status and provision of social history in museums and the standards of collections, research, display and interpretation' www.shcg.org.uk/Home

20 Outreach group interview by author, digital recording, 2013.

There is also a temporal form of accountability that is particular to the museum linked to the custodian role of the museum (Gray 2011: 54). There are further tensions here in managing $\mathrm{CE}$ as a present concern as it requires creating a balance between now and the future, and between specific individuals and 'the public interest'. As Graham et al. (2013: 107) make clear, the use of 'public' in museums is not a neutral description of what museums 'do', since public interest "comes through museum professionals' imagination." The 'public' isn't manifest: it is an idea that the museum calls into being when it frames its accountability to it. This further highlights how accountability clearly presents a conceptual frame for further research through which to reconsider the different stakes of participation/ community engagement in the museum.

23 Curatorial Team member, interview by author, digital recording, 2012; author's emphasis.

\section{References}

Adair, B., Filene, B. and Koloski, L. (eds) (2011) Letting Go?: sharing historical authority in a user-generated world, Philadelphia, PA: Pew Center for Arts \& Heritage.

Ames, M.M. (2003) 'How to decorate a house: the renegotiation of cultural representation at the University of British Colombia Museum of Anthropology', in Laura Peers and Alison Brown (eds) Museums and source communities: a Routledge reader, 171180, London: Routledge.

Arnstein, S.R. (1969) 'A Ladder Of Citizen Participation', Journal of the American Institute of Planners, 35 (4) 216-24.

Askew, L.E. (2009) '“At home" in state institutions: The caring practices and potentialities of human service workers', Geoforum, 40 (4) 655-63.

Bellamy, R. and Palumbo, A. (eds) (2010) Political Accountability, Farnham: Ashgate.

Bennett, T. (1992) 'Putting policy into cultural studies', in L. Grossberg, C. Nelson and P.A. Treichler (eds) Cultural studies, 23-37, New York and London: Routledge.

Boast, R. (2011) 'Neocolonial collaboration: Museum as Contact Zone Revisited', Museum Anthropology, 34 (1) 56-70.

Carnegie, G.D. and Wolnizer, P.W. (1996) 'Enabling accountability in museums', Accounting, Auditing \& Accountability Journal, 9 (5) 84-99. 
Clifford, J. (1997) Routes: travel and translation in the late twentieth century, Cambridge, MA: Harvard University Press.

Fleming, D., Paine, C. and Rhodes, J.G. (eds) (1993) Social History in Museums: A Handbook for Professionals, HM Stationery Office.

Fouseki, K. (2010) "Community voices, curatorial choices": community consultation for the 1807 exhibitions', museum and society, 8 (3) 180-92.

Golding, V. and Modest, W. (eds) (2013) Museums and communities: curators collections and collaboration, London: Bloomsbury.

Graham, H. (2012) ‘Scaling Governmentality’, Cultural Studies, 26 (4) 565-92.

Graham, H., Mason, R. and Nayling, N. (2013) 'The Personal is still Political: Museums, Participation and Copyright', museum and society, 11 (1) 105-21.

Gray, C. (2008) 'Instrumental policies: causes, consequences, museums and galleries', Cultural Trends, 17 (4) 209-22.

Gray, C. (2011) 'Museums, Galleries, Politics and Management', Public Policy and Administration, 26 (1) 45-61.

Gray, C. (2014) "Cabined, cribbed, confined, bound in" or "we are not a government poodle": Structure and agency in museums and galleries', Public Policy and Administration, 29 (3) 185-203.

Harmon, M.M. and Mayer, R.T. (1986) Organization Theory for Public Administration, London: Little, Brown \& Company.

Hatch, M.J. and Cunliffe, A.L. (2006) Organization theory: modern, symbolic, and postmodern perspectives, 2nd ed. Oxford: Oxford University Press.

Hetherington, K. (2003) 'Accountability and disposal : visual impairment and the museum', museum and society, 1 (2) 104-15.

Karp, I. and Kratz, C.A. (2006) 'Introduction: Museum frictions: public cultures/global transformations', in I. Karp, C. A. Kratz, L. Swaja, and T. Ybarra-Frausto, (eds) Museum frictions: public cultures/global transformations, 1-34, Durham, NC: Duke University Press.

Karp, I. and Lavine, S.D. (eds) (1991) Exhibiting cultures: the poetics and politics of museum display, Washington: Smithsonian Institution Press.

Kirkpatrick, I. and Ackroyd, S. (2003) 'Archetype Theory and the Changing Professional Organization: A Critique and Alternative', Organization, 10 (4) 731-50.

Lawley, I. (2003) 'Local authority museums and the modernizing government agenda in England', museum and society, 1 (2) 75-86.

Lynch, B.T. (2011a) 'Collaboration, contestation and creative conflict: on the efficacy of museum/community partnerships', in Janet Marstine, (ed) The Routledge Companion to Museum Ethics: Redefining Ethics for the Twenty-First Century Museum, 146-64, London, Routledge,

(2011b) 'Custom-made reflective practice: can museums realise their capabilities in helping others realise theirs?' Museum Management and Curatorship, 26 (5) 441-58. 
(2011c) Whose cake is it anyway? A collaborative investigation into engagement and participation in 12 museums and galleries in the UK, London: Paul Hamlyn Foundation.

(2013) 'Reflective debate, radical transparency and trust in the museum', Museum Management and Curatorship, 28 (1) 1-13.

Lynch, B.T. and Alberti, S.J.M.M. (2010) 'Legacies of prejudice: racism, co-production and radical trust in the museum', Museum Management and Curatorship, 25 (1) 13-35.

Macdonald, S. (2002) Behind the Scenes at the Science Museum, Oxford: Berg.

Marstine, J. ed. (2011) The Routledge Companion to Museum Ethics: Redefining Ethics for the Twenty-First Century Museum, London: Routledge.

McCall, V. and Gray, C. (2014) 'Museums and the "new museology": theory, practice and organisational change', Museum Management and Curatorship, 29 (1) 19-35.

McSweeney, K. and Kavanagh, J. (eds) (2016) Museum Participation: New Directions for Audience Collaboration, Edinburgh and Boston: MuseumsEtc.

Message, K. (2014) Museums and social activism: engaged protest, Museum meanings, New York: Routledge.

Moncrieffe, J. (2011) Relational accountability: complexities of structural injustice, London and New York: Zed Books.

Morse, N., Macpherson, M. and Robinson, S. (2013) 'Developing dialogue in co-produced exhibitions: between rhetoric, intentions and realities', Museum Management and Curatorship, 28 (1) 91-106.

Morse, N. and Munro, E. (2018) 'Museums' community engagement schemes, austerity and practices of care in two local museum services', Social \& Cultural Geography, 19 (3) 357-78.

Munro, E. (2014) 'Doing emotion work in museums: reconceptualising the role of community engagement practitioners', museum and society, 12 (1) 44-60.

Neyland, D. and Woolgar, S. (2002) 'Accountability in action?: the case of a database purchasing decision', The British Journal of Sociology, 53 (2) 259-74.

O’Neill, M. (2008) 'Museums, professionalism and democracy', Cultural Trends, 17 (4) 289-307.

Peers, L.L. and Brown, A.K. (eds) (2003) Museums and source communities: a Routledge reader, London: Routledge.

Phillips, R. (2003) 'Community Collaborations in Exhibitions: Towards a Dialogic Paradigm. Introduction', in Laura Peers and Alison Brown (eds) Museums and source communities: a Routledge reader, 156-70, London: Routledge,

Sandell, R. (ed) (2002) Museums, society, inequality, London: Routledge.

(2003) 'Social Inclusion, the museum and the dynamics of sectoral change', museum and society, 1 (1) 45-62.

Sandell, R. and Janes, R.R. (eds) (2007) Museum management and marketing, Leicester readers in Museum Studies, London and New York: Routledge. 
Sandell, R. and Nightingale, E. (eds) (2012) Museums, equality, and social justice, London: Routledge.

Shore, C. and Wright, S. (2000) 'Coercive accountability: the rise of audit culture in higher education', in M. Strathern (ed) Audit cultures: anthropological studies in accountability, ethics and the academy, 57-90, London: Routledge.

Simon, N. (2010) The Participatory Museum, Museum 2.0.

Sinclair, A. (1995) 'The chameleon of accountability: Forms and discourses', Accounting, Organizations and Society, 20 (2) 219-37.

Strathern, M. (2000) Audit cultures: anthropological studies in accountability, ethics and the academy, London: Routledge.

Tapsell, P. (2014) 'Ko Tawa: where are the glass cabinets?', in R. Silverman (ed) Museum as Process: Translating Local and Global Knowledges, 262-78, London and New York: Routledge.

Tlili, A. (2008) 'Behind the Policy Mantra of the Inclusive Museum: Receptions of Social Exclusion and Inclusion in Museums and Science Centres', Cultural Sociology, 2 (1) 123-47.

(2014) 'Managing performance in publicly funded museums in England: effects, resistances and revisions', International Journal of Heritage Studies, 20 (1) 157-80.

(2016) 'In Search of Museum Professional Knowledge Base: Mapping the professional knowledge debate onto museum work', Educational Philosophy and Theory, 48 (11) 1100-22.

Tlili, A., Gewirtz, S. and Cribb, A. (2007) 'New Labour's socially responsible museum: roles, functions and greater expectations', Policy Studies, 28 (3) 269-89.

Weick, K.E. (1995) Sensemaking in organizations, Foundations for organizational science, Thousand Oaks, Calif. and London: Sage.

Weick, K.E., Sutcliffe, K.M. and Obstfeld, D. (2005) 'Organizing and the Process of Sensemaking', Organization Science, 16 (4) 409-21.

*Nuala Morse is a Lecturer in Museum Studies at the University of Leicester. Her work is focused on museum work and care, as ethics and practice, and in relation to organizational change. She has published about community engagement, the co-production of exhibitions, and participatory research in museums. She has previously worked on a research project looking at the health and well-being benefits of museum participation.

Nuala Morse

School of Museum Studies,

University of Leicester,

19 University Road,

Leicester, LE1 7RF, UK

Tel: +44 (0)116 2523975

Email: nuala.morse@leicester.ac.uk

Twitter: @nualamorse 